\title{
No Renal Toxicity After Repeated Treatment with Pressurized Intraperitoneal Aerosol Chemotherapy (PIPAC) in Patients with Unresectable Peritoneal Metastasis
}

\author{
VIRGINIE LARBRE $^{1}$, MOHAMMAD ALYAMI $^{2,3,4}$, FREDERIC MERCIER ${ }^{2,5}$, NICOLAS VANTARD ${ }^{1}$, \\ ISABELLE BONNEFOY ${ }^{2,3}$, MARIE-AGNÈS OPSOMER ${ }^{1}$, LAURENT VILLENEUVE ${ }^{3,6}$, \\ NAOUAL BAKRIN ${ }^{2,3}$, CATHERINE RIOUFOL ${ }^{1}$, OLIVIER GLEHEN ${ }^{2,3}$ and VAHAN KEPENEKIAN ${ }^{2,3}$ \\ ${ }^{1}$ Department of Clinical Oncology Pharmacy, Centre Hospitalier Lyon-Sud, \\ Hospices Civils de Lyon, Pierre-Bénite, France; \\ ${ }^{2}$ Department of Surgical Oncology, Centre Hospitalier Lyon-Sud, Hospices Civils de Lyon, Pierre-Bénite, France; \\ ${ }^{3}$ EMR 3738, Lyon 1 University, Lyon, France; \\ ${ }^{4}$ Department of General Surgery and Surgical Oncology, \\ King Faisal Specialist Hospital \& Research Center, Riyadh, Saudi Arabia; \\ ${ }^{5}$ Department of Surgical Oncology, Centre Hospitalo-Universitaire de Montreal, Montreal, Canada; \\ ${ }^{6}$ Clinical Research Unit, Department of Public Health, Hospices Civils de Lyon, Pierre-Bénite, France
}

\begin{abstract}
Background/Aim: Pressurized intraperitoneal aerosol chemotherapy (PIPAC) is a recent approach for intraperitoneal chemotherapy with promising results for patients with peritoneal metastasis (PM). The aim of this study was to report renal toxicity for patients who received at least 3 repeated PIPAC procedures. Patients and Methods: All patients who underwent at least 3 PIPAC cycles of cisplatin $\left(7.5 \mathrm{mg} / \mathrm{m}^{2}\right)$ and doxorubicin $\left(1.5 \mathrm{mg} / \mathrm{m}^{2}\right)$ for unresectable PM from December 2015 to September 2017, were analysed regarding postoperative renal toxicity. Results: Among 103 patients registered in a prospective single center database, 43 patients underwent at least 3 PIPAC cycles representing a total of 175 PIPAC. Median age was 59.8 years, $24(55.8 \%)$ patients were female and median BMI was $22.2 \mathrm{~kg} / \mathrm{m}^{2}$. Most common origins of PM were gastric $22(51.1 \%)$ and ovarian $11(25.6 \%)$ cancer. Median peritoneal cancer index (PCI) was 17 (range=5-39). For 39 (90.1\%) patients, systemic chemotherapy was performed in addition to PIPAC. Forty-three (100\%), 17 (39.5\%), 14 (32.5\%), 8 (18.6\%), 3 (7\%), $2(4.7 \%)$ and $2(4.7 \%)$ patients underwent three, four, five, six, seven, eight and nine PIPAC
\end{abstract}

Correspondence to: Mohammad Alyami, MD, Department of Surgical Oncology, Lyon-Sud University Hospital, 165 Chemin du Grand Revoyet, 69495 Pierre-Bénite, France. Tel: +33 478861377, Fax: +33 478863343, e-mail: swar_ms@hotmail.com

Key Words: Peritoneal metastasis, cisplatin, doxorubicin, cancer, peritoneum, surgery. procedures, respectively. Repeated PIPAC did not induce significant acute nor cumulative renal toxicity in any patients. Conclusion: Repeated PIPAC did not induce clinically relevant renal toxicity. This study confirms the previous published results in a larger group of patients.

Peritoneal metastasis (PM) is a common evolution of abdominal cancers and is associated with a poor prognosis in the absence of aggressive multimodal therapeutic approaches (1). Systemic chemotherapy offers suboptimal effects in terms of outcomes due to a weak penetration of agents in the peritoneum and a relative resistance of peritoneal nodules (2, 3). When PM is unresectable, systemic chemotherapies associated with targeted therapies are actually the only treatments with limited effect on survival. Expected median survival reaches 20 months for colorectal cancer (4), 7 months for gastric cancer (5), 17.6 months for ovarian cancer (6), and less than 12 months for peritoneal mesothelioma (7). Cytoreductive surgery (CRS) with hyperthermic intraperitoneal chemotherapy (HIPEC) in adjunct to perioperative systemic chemotherapy was developed in the 90's for selected patients with resectable PM $(8,9)$. It has improved the median overall survival (OS) and is nowadays one of the standard therapies for several pathologies, such as pseudomyxoma peritonei, mesothelioma, colorectal, ovarian and gastric PM (10-14).

For unresectable PM a minimally-invasive repeatable approach has recently been developed: pressurized intraperitoneal aerosol chemotherapy (PIPAC). It seems to enhance the effect of chemotherapy by taking advantage of the physical properties of aerosol and pressure (15). PIPAC is reported to 
be safe and well tolerated, with no postoperative hepatic and renal toxicities (16-21). The first evidence of PIPAC efficacy were promising, regression of PM in tumors resistant to systemic chemotherapy has been reported (15).

The aim of the present study was to report renal toxicity in patients who received at least 3 repeated PIPAC procedures of cisplatin $\left(7.5 \mathrm{mg} / \mathrm{m}^{2}\right)$ and doxorubicin $\left(1.5 \mathrm{mg} / \mathrm{m}^{2}\right)$.

\section{Patients and Methods}

Study design. The study included patients with unresectable PM who underwent at least 3 repeated PIPAC procedures with cisplatin $\left(7.5 \mathrm{mg} / \mathrm{m}^{2}\right)$ and doxorubicin $\left(1.5 \mathrm{mg} / \mathrm{m}^{2}\right)$ every 6 to 8 weeks in conjunction with 2 interval systemic chemotherapies between December 2015 and September 2017 at Lyon-Sud university hospital. The patient data were extracted from the BIG-RENAPE database (NCT02823860).

Our center followed the PIPAC implementation training program for practical and safety procedures organized by Professor Reymond in Germany in addition to a visit in an active PIPAC center before starting the 1st procedure. The study was performed in accordance with the precepts established by the Declaration of Helsinki. All patients gave their written informed consent for data collection.

Study population. Before therapy, every case was presented to the multidisciplinary tumor board and the indication for PIPAC procedure was decided in an individual, case-by-case basis. The PIPAC approach was only considered for patients with unresectable PM with an Eastern Cooperative Oncology Group (ECOG) performance status $<2$. Patients with intestinal obstruction, extraperitoneal disease, or a history of allergic reactions to platinum compounds or doxorubicin were not considered.

For each patient who underwent PIPAC procedures, the following data were extracted: gender, age at the time of first PIPAC procedure, origin of PM, body mass index (BMI), history of chemotherapy lines before PIPAC, type of systemic chemotherapy in conjunction with PIPAC, extent of PM determined according to the Peritoneal Cancer Index (PCI) (22), delay between PIPAC and systemic chemotherapy, blood creatinine (Creat), and blood urea nitrogen (BUN).

Surgical procedure. The technique used at our institution was previously described $(23,24)$. In brief, under general anaesthesia without hyper hydration, a balloon trocar (Applied Medical, Paris, France) was placed in the midline, using open laparoscopic access technique, and a capnoperitoneum insufflation of $12 \mathrm{mmHg}$ at $37^{\circ} \mathrm{C}$ was applied. Another balloon trocar was placed in the midline. Explorative laparoscopy was performed and the PCI was determined. Parietal biopsies were performed and ascites was removed for peritoneal cytology. A nebulizer CAPNOPEN ${ }^{\circledR}$ (Reger Medizintechnik, GmbH, Villingendorf, Germany) was then connected to a high-pressure injector and inserted into the abdomen through a trocar. The safety protocol with a checklist containing all safety aspects, as described previously $(16,18)$, was systematically double-checked before administration of cytotoxic drugs. A pressurized aerosol containing chemotherapy agents was then applied. The chemotherapies administrated were cisplatin $\left(7.5 \mathrm{mg} / \mathrm{m}^{2}\right.$ body surface in $150 \mathrm{ml} \mathrm{NaCl} 0.9 \%$ ) immediately followed by doxorubicin $\left(1.5 \mathrm{mg} / \mathrm{m}^{2}\right.$ in $\left.50 \mathrm{ml} \mathrm{NaCl} 0.9 \%\right)$. Application time was
30 min. Remaining toxic aerosol was exhausted over a closed surgical smoke evacuation system. Trocars were removed. The goal was to repeat PIPAC every 6 to 8 weeks for at least three times.

Sampling. Peripheral venous blood (for Creatinine and urea clearances) was routinely collected preoperatively and then on the 3rd postoperative day. Analysis was performed in the clinical chemistry laboratory of our hospital according to routine protocols. Toxicity was assessed by measuring blood creatinine (Creat) $(\mu \mathrm{mol} / \mathrm{l})$ and blood urea nitrogen $(\mathrm{BUN})(\mu \mathrm{mol} / \mathrm{l})$. Acute renal dysfunction was defined as a $>50 \%$ increase in post-treatment creatinine according to Risk, Injury, Failure, Loss of kidney function, and End stage kidney disease (RIFLE) and Acute Kidney Injury Network (AKIN) classification $(25,26)$.

Ethical approval. All procedures performed in studies involving human participants were in accordance with the ethical standards of the institutional and/or national research committee and with the 1964 Helsinki declaration and its later amendments or comparable ethical standards.

Statistical analysis. Descriptive results were presented as a number (percentage) for qualitative variables and as a mean \pm standard deviation (SD) or median (minimum-maximum) for quantitative variables.

\section{Results}

Among 103 patients registered in our database between December 2015 and September 2017, 43 patients underwent at least 3 PIPAC cycles with a total of 175 PIPAC (Table I). Median age was 59.8 years, $24(55.8 \%)$ patients were female and median BMI was 22.2. The most common origins of PM were gastric $22(51.1 \%)$ and ovarian 11 (25.6\%) cancer. Median PCI was 17 (5-39). In 39 (90.1\%) patients, systemic chemotherapy was performed in addition to PIPAC. Fortythree (100\%), 17 (39.5\%), 14 (32.5\%), 8 (18.6\%), 3 (7\%), 2 $(4.7 \%)$ and $2(4.7 \%)$ patients underwent three, four, five, six, seven, eight and nine PIPAC, respectively. Repeated PIPAC did not induce significant acute nor cumulative renal toxicity in all patients (Figure 1). Renal function remained stable even after 9 PIPAC cycles in some patients.

\section{Discussion}

Our study confirmed that repeated PIPAC did not induce significant acute or cumulative renal toxicity. This is remarkable since application of PIPAC was repeated up to 9 cycles in some patient at 6 to 8 -week intervals.

Intravenous chemotherapy aims to control systemic disease. But, because of interstitial fibrosis and the effective barrier between blood and the peritoneal cavity, drug concentrations penetrating in peritoneal tumour nodules are low and systemic toxicity is important (27). Drugs mostly used for systemic chemotherapy combine taxanes such as paclitaxel and platinumbased anticancer agents including cisplatin or carboplatin, 
Table I. Clinicopathological data for patients treated with PIPAC ${ }^{a}$.

\begin{tabular}{|c|c|c|}
\hline Variable & Value $\mathrm{N}$ & Percentage \\
\hline Number of patients & 43 & \\
\hline Gender (M:F) & $19: 24$ & $44.2: 55.8$ \\
\hline Age, median years (range) & $59.8(33-77.9)$ & \\
\hline BMI, median & 22.2 & \\
\hline \multicolumn{3}{|l|}{ Origin of PC } \\
\hline Gastric & 22 & 51.1 \\
\hline Ovarian & 11 & 25.6 \\
\hline Mesothelioma & 4 & 9.3 \\
\hline Pseudomyxoma & 2 & 4.7 \\
\hline Others & 4 & 9.3 \\
\hline Synchronous PC & 32 & 74.4 \\
\hline Metachronous PC & 11 & 25.6 \\
\hline \multicolumn{3}{|l|}{ Preoperative Chemotherapy } \\
\hline 1 line & 39 & 90.1 \\
\hline 2 lines & 23 & 53.5 \\
\hline 3 lines & 6 & 12 \\
\hline Systemic chemotherapy associated with PIPAC & 39 & 90.1 \\
\hline Median PCI at time of first PIPAC & $17(5-39)$ & \\
\hline PIPAC sessions & 175 & \\
\hline 1 & 43 & 100 \\
\hline 2 & 43 & 100 \\
\hline 3 & 43 & 100 \\
\hline 4 & 17 & 39.5 \\
\hline 5 & 14 & 32.5 \\
\hline 6 & 8 & 18.6 \\
\hline 7 & 3 & 7 \\
\hline 8 & 2 & 4.7 \\
\hline 9 & 2 & 4.7 \\
\hline
\end{tabular}

aValues in table are numbers of patients (percentages) unless otherwise indicated.

known to cause tubular necrosis and renal failure $(28,29)$. Indeed, the main elimination route of cisplatin is renal: the drug and its metabolites reach high local concentrations leading to dose-dependent renal toxicity $(30,31)$.

On the other hand, loco-regional delivery of chemotherapy into the abdominal cavity is nowadays recognized as a safe option for PM treatment in selected patients, represented by HIPEC after CRS for resectable PM. For unresectable PM, PIPAC seems to enhance the effect of chemotherapy (15). Multiples recent studies demonstrated the absence of postoperative renal toxicity related to $\operatorname{PIPAC}(17,32,33)$. Blanco et al. have reported that renal function remained within the normal range with no cumulative toxicity after two to three PIPAC sessions in three patients included in their study (17). Robella et al. have shown that the association of PIPAC and systemic chemotherapy does not induce significant renal toxicity (32). Finally, Teixeira Farinha et al., reported that creatinine levels were not significantly altered after PIPAC procedures at post-operative day 2 even when procedures were repeated (33). The present findings confirm previously reported results on a larger scale and suggest that repeated PIPAC does not induce significant acute nor cumulative renal toxicity even after 9 PIPAC.

Nephrotoxicity, the major dose-limiting adverse effect of cisplatin treatment, has also been reported in HIPEC. It is partly explained by cisplatin's concentration into the circulation as previously showed by pharmacokinetic studies. Cisplatin treatment results in acute cytotoxicity to tubular epithelium, followed by inflammatory cell infiltration and fibroproliferative changes (34). In most of the PIPAC literature, cisplatin dose was $7.5 \mathrm{mg} / \mathrm{m}^{2}$ and doxorubicin dose was $1.5 \mathrm{mg} / \mathrm{m}^{2}$. The lack of systemic toxicity might reflect the fact that PIPAC achieves high intraabdominal concentrations of chemotherapy while minimal amounts of the drug reach systemic circulation (35). In our study, repeated PIPAC were found to be completely safe for the kidney even after 9 PIPAC at these concentrations. In a recent phase I study evaluating cisplatin dose escalation in PIPAC, there was no renal toxicity even with higher dose of cisplatin (34). They concluded that PIPAC with cisplatin and doxorubicin may be safely used at an intraperitoneal dose of $10.5 \mathrm{mg} / \mathrm{m}^{2}$ and $2.1 \mathrm{mg} / \mathrm{m}^{2}$, respectively. Therefore, for selected patients, like older 

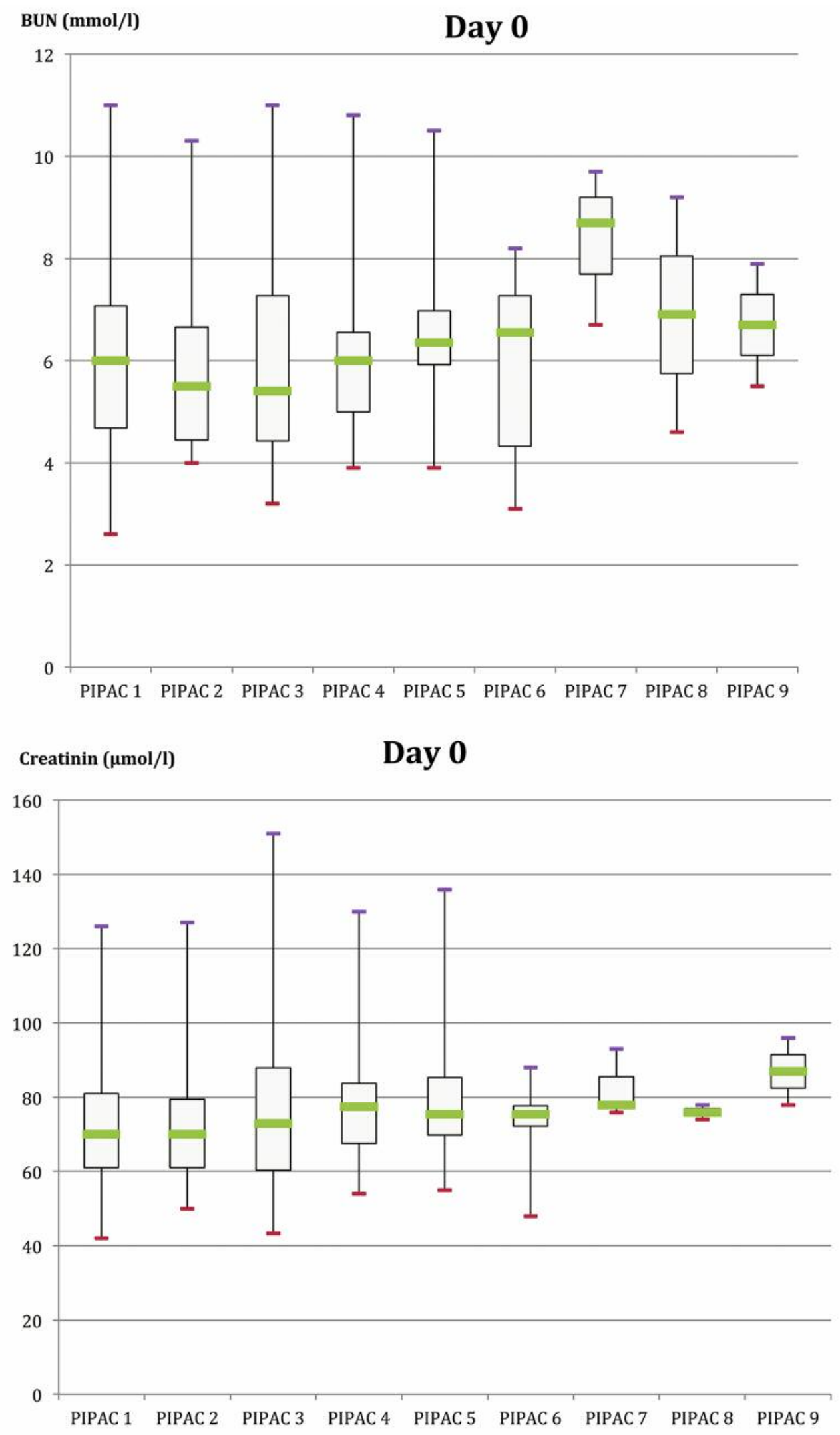

Figure 1. Continued 
BUN (mmol/l)

Day 3

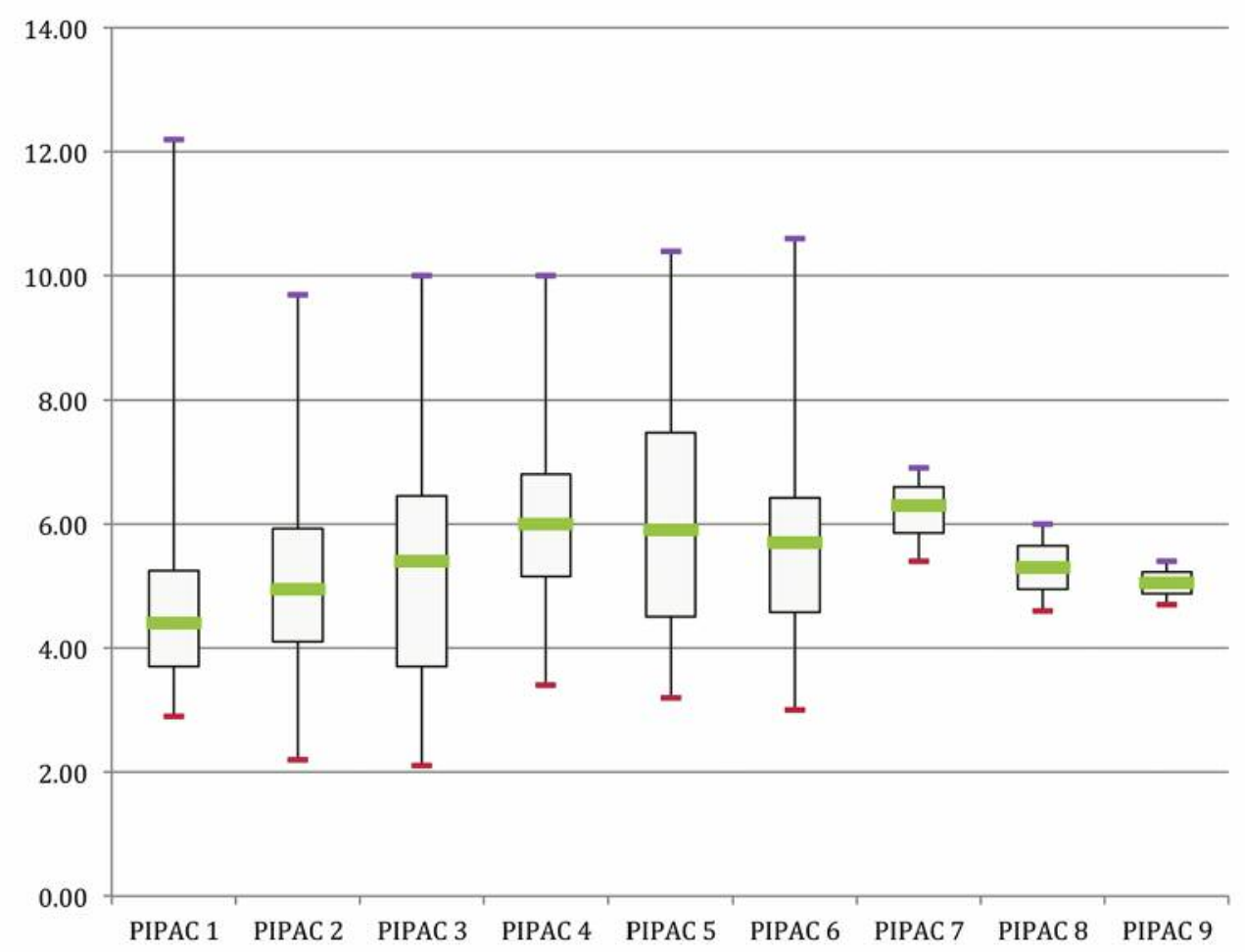

Creatinin $(\mu \mathrm{mol} / \mathrm{l})$

Day 3

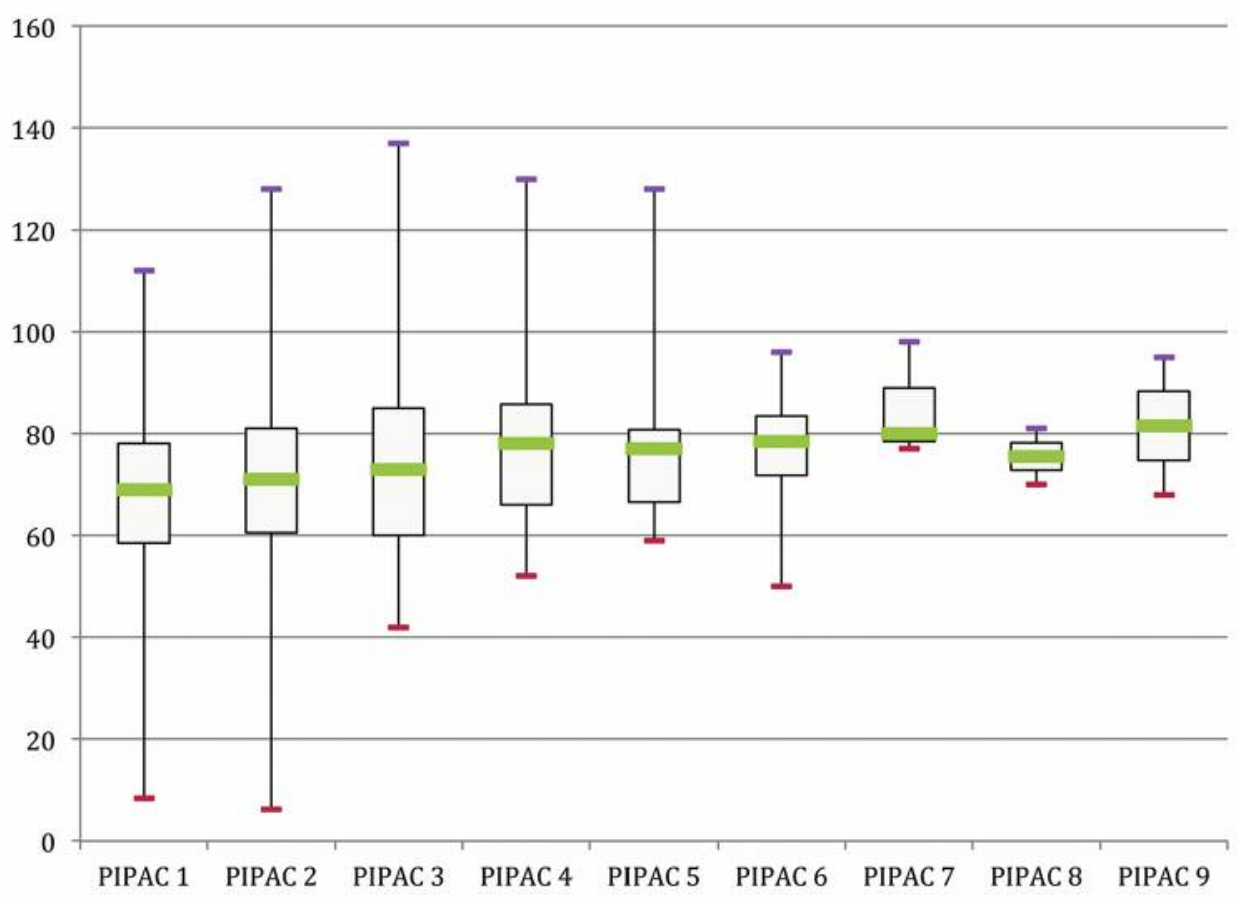

Figure 1. Renal toxicity after repetitive PIPAC procedures. Renal toxicity under PIPAC treatment represented by BUN and Creatinine levels. A) BUN at day 0. B) Creatinine at day 0. C) BUN at day 3 post PIPAC. D) Creatinine at day 3 post PIPAC. No significant difference was found for repetitive PIPAC up to 9 procedures. BUN - Blood urea nitrogen. 
patients(36) or patients who experienced severe toxic effects from previous systemic chemotherapy, even chronic renal failure, PIPAC might be promising.

The data reported herein should be evaluated in the context of their limitations. First, this study represents a retrospective analysis of patients treated at a single institution. However, the database used is prospectively maintained and managed by a trained, full time personnel using abstracted data and standardised algorithms similar to those used in the management of large, national data sets. Second, the population was heterogeneous regarding PC origins, number of PIPAC procedures applied, number of previous chemotherapy lines and nature of systemic chemotherapy associated to PIPAC. However, evolution of renal function is similar, which demonstrates the safety of PIPAC procedure. The last limitation was the absence of long-term patient's follow-up.

\section{Conclusion}

Repeated PIPAC did not induce clinically relevant renal toxicity. This study confirms the previous published results in a larger group of patients.

\section{Conflicts of Interest}

The Authors report no conflicts of interest relevant to this article.

\section{References}

1 Sadeghi B, Arvieux C, Glehen O, Beaujard AC, Rivoire M, Baulieux J, Fontaumard E, Brachet A, Caillot JL, Faure JL, Porcheron J, Peix JL, François Y, Vignal J and Gilly FN: Peritoneal carcinomatosis from non-gynecologic malignancies: results of the EVOCAPE 1 multicentric prospective study. Cancer 88(2): 358-363, 2000.

2 Minchinton AI and Tannock IF: Drug penetration in solid tumours. Nat Rev Cancer 6(8): 583-592, 2006.

3 Markman M: Intraperitoneal antineoplastic drug delivery: rationale and results. Lancet Oncol 4(5): 277-283, 2003.

4 Elias D, Gilly F, Boutitie F, Quenet F, Bereder JM, Mansvelt B, Lorimier G, Dube P and Glehen O: Peritoneal colorectal carcinomatosis treated with surgery and perioperative intraperitoneal chemotherapy: retrospective analysis of 523 patientsfrom a multicentric French study. J Clin Oncol 28(1): 63-68, 2010.

5 Rivera F, Vega-Villegas ME and Lopez-Brea MF: Chemotherapy of advanced gastric cancer. Cancer Treat Rev 33(4): 315-324, 2007.

6 Hanker LC, Loibl S, Burchardi N, Pfisterer J, Meier W, PujadeLauraine E, Ray-Coquard I, Sehouli J, Harter P and du Bois A: The impact of second to sixth line therapy on survival of relapsed ovarian cancer after primary taxane/platinum-based therapy. Ann Oncol 23(10): 2605-2612, 2012.

7 Chua TC, Yan TD and Morris DL: Surgical biology for the clinician: peritoneal mesothelioma: current understanding and management. Can J Surg 52(1): 59-64, 2009.
8 Sugarbaker PH, Cunliffe WJ, Belliveau J, de Bruijn EA, Graves T, Mullins RE and Schlag P: Rationale for integrating early postoperative intraperitoneal chemotherapy into the surgical treatment of gastrointestinal cancer. Semin Oncol 16: 83-97, 1989.

9 Gilly FN, Sayag AC, Carry PY, Braillon GG, James IM, Volloch $\mathrm{AA}$ and Panteix GG: Intra-Peritoneal Chemo-Hyperthermia (CHIP): a new therapy in the treatment of the peritoneal seedings. Preliminary report. Int Surg 76(3): 164-167, 1991.

10 Chua TC, Moran BJ, Sugarbaker PH, Levine EA, Glehen O, Gilly FN, Baratti D, Deraco M, Elias D, Sardi A, Liauw W, Yan TD, Barrios P, Gomez Portilla A, de Hingh IH, Ceelen WP, Pelz JO, Piso P, Gonzalez-Moreno S, Van Der Speeten K andMorris DL: Early- and long-term outcome data of patients with pseudomyxoma peritonei from appendiceal origin treated by a strategy of cytoreductive surgery and hyperthermic intraperitoneal chemotherapy. J Clin Oncol 130(20): 2449-2456, 2012.

11 Yan TD, Deraco M, Baratti D, Kusamura S, Elias D, Glehen O, Gilly FN, Levine EA, Shen P, Mohamed F, Moran BJ, Morris DL, Chua TC, Piso P and Sugarbaker PH: Cytoreductive surgery and hyperthermic intraperitoneal chemotherapy for malignant peritoneal mesothelioma: multi-institutional experience. J Clin Oncol 27(36): 6237-6242, 2009.

12 Goere D, Malka D, Tzanis D, Gava V, Boige V, Eveno C, Maggiori L, Dumont F, Ducreux M and Elias D: Is there a possibility of a cure in patients with colorectal peritoneal carcinomatosis amenable to complete cytoreductive surgery and intraperitoneal chemotherapy? Ann Surg 257(6): 1065-1071, 2013.

13 Chia CS, You B, Decullier E, Vaudoyer D, Lorimier G, Abboud K, Bereder JM, Arvieux C, Boschetti G and Glehen O: Patients with peritoneal carcinomatosis from gastric cancer treated with cytoreductive surgery and hyperthermic intraperitoneal chemotherapy: Is cure a possibility? Ann Surg Oncol 23(6): 1971-1979, 2016.

14 van Driel WJ, Koole SN, Sikorska K, Schagen van Leeuwen JH, Schreuder HWR, Hermans RHM, de Hingh I, van der Velden J, Arts, HJ, Massuger L, Aalbers AGJ, Verwaal VJ, Kieffer JM, Van de Vijver KK, van Tinteren H, Aaronson NK and Sonke G S: Hyperthermic intraperitoneal chemotherapy in ovarian cancer. $\mathrm{N}$ Engl J Med 378(3): 230-240, 2018.

15 Solass W, Kerb R, Murdter T, Giger-Pabst U, Strumberg D, Tempfer C, Zieren J, Schwab M and Reymond MA: Intraperitoneal chemotherapy of peritoneal carcinomatosis using pressurized aerosol as an alternative to liquid solution: first evidence for efficacy. Ann Surg Oncol 21(2): 553-559, 2014.

16 Solass W, Giger-Pabst U, Zieren J and Reymond MA: Pressurized intraperitoneal aerosol chemotherapy (PIPAC): occupational health and safety aspects. Ann Surg Oncol 20(11): 3504-3511, 2013.

17 Blanco A, Giger-Pabst U, Solass W, Zieren J and Reymond MA: Renal and hepatic toxicities after pressurized intraperitoneal aerosol chemotherapy (PIPAC). Ann Surg Oncol 20(7): 23112316, 2013.

18 Hubner M, Grass F, Teixeira-Farinha H, Pache B, Mathevet P and Demartines N: Pressurized Intraperitoneal aerosol chemotherapy - Practical aspects. Eur J Surg Oncol 43(6): 1102-1109, 2017.

19 Grass F, Vuagniaux A, Teixeira-Farinha H, Lehmann K, Demartines $\mathrm{N}$ and Hubner M: Systematic review of pressurized intraperitoneal aerosol chemotherapy for the treatment of advanced peritoneal carcinomatosis. Br J Surg 104(6): 669-678, 2017. 
20 Hubner M, Teixeira Farinha H, Grass F, Wolfer A, Mathevet P, Hahnloser D and Demartines N: Feasibility and safety of pressurized intraperitoneal aerosol chemotherapy for peritoneal carcinomatosis: A retrospective cohort study. Gastroenterol Res Pract 68(5): 274-279, 2017.

21 Tempfer CB, Rezniczek GA, Ende P, Solass W and Reymond MA: Pressurized intraperitoneal aerosol chemotherapy with cisplatin and doxorubicin in women with peritoneal carcinomatosis: A Cohort Study. Anticancer Res 35(12): 6723-6729, 2015.

22 Jacquet $\mathrm{P}$ and Sugarbaker P: Clinical research methodologies in diagnosis and staging of patients with peritoneal carcinomatosis Cancer Treat Res 82: 359-374, 1996.

23 Alyami M, Gagniere J, Sgarbura O, Cabelguenne D, Villeneuve L, Pezet D, Quenet F, Glehen O, Bakrin N and Passot G: Multicentric initial experience with the use of the pressurized intraperitoneal aerosol chemotherapy (PIPAC) in the management of unresectable peritoneal carcinomatosis. Eur J Surg Oncol 43(11): 2178-2183, 2017.

24 Cazauran JB, Alyami M, Lasseur A, Gybels I, Glehen O and Bakrin N: Pressurized intraperitoneal aerosol chemotherapy (PIPAC) procedure for non-resectable peritoneal carcinomatosis (with Video). J Gastrointest Surg 22(2): 374-375, 2017.

25 Kellum JA, Levin N, Bouman C and Lameire N: Developing a consensus classification system for acute renal failure. Curr Opin Crit Care 8(6): 509-514, 2002.

26 Bellomo R, Ronco C, Kellum JA, Mehta RL and Palevsky P: Acute renal failure - definition, outcome measures, animal models, fluid therapy and information technology needs: the Second International Consensus Conference of the Acute Dialysis Quality Initiative (ADQI) Group. Crit Care 8(4): 204212, 2004.

27 Hubner M, Teixeira H, Boussaha T, Cachemaille M, Lehmann $\mathrm{K}$ and Demartines N: PIPAC--Pressurized intraperitoneal aerosol chemotherapy. A novel treatment for peritoneal carcinomatosis. Rev Med Suisse 11(479): 1325-1330, 2015.

28 Bakrin N, Classe JM, Pomel C, Gouy S, Chene G and Glehen $\mathrm{O}$ : Hyperthermic intraperitoneal chemotherapy (HIPEC) in ovarian cancer. J Visc Surg 151(5): 347-353, 2014.
29 Castro-Maesta JF, González-Guerrero JF, Barrios-Sánchez P and Villarreal-Cavazos G: Bases and foundations of the treatment of peritoneal carcinomatosis: Review article. Medicina Universitaria 18(71): 98-104, 2016.

30 Oh GS, Kim HJ, Shen A, Lee SB, Khadka D, Pandit A and So HS: Cisplatin-induced kidney dysfunction and perspectives on improving treatment strategies. Electrolyte Blood Press 12(2): 55-65, 2014.

31 Ozkok A and Edelstein CL: Pathophysiology of cisplatininduced acute kidney injury. Biomed Res Int 96(7): 82-86, 2014.

32 Robella M, Vaira M and De Simone M: Safety and feasibility of pressurized intraperitoneal aerosol chemotherapy (PIPAC) associated with systemic chemotherapy: an innovative approach to treat peritoneal carcinomatosis. World J Surg Oncol 14: 12$18,2016$.

33 Teixeira Farinha H, Grass F, Labgaa I, Pache B, Demartines N and Hubner $\mathrm{M}$ : Inflammatory response and toxicity after pressurized intraperitoneal aerosol chemotherapy. J Cancer 9(1): 13-20, 2018.

34 Miller RP, Tadagavadi RK, Ramesh $G$ and Reeves WB: Mechanisms of Cisplatin nephrotoxicity. Toxins 2(11): 24902518, 2010.

35 Tempfer CB, Giger-Pabst U, Seebacher V, Petersen M, Dogan A and Rezniczek GA: A phase I, single-arm, open-label, dose escalation study of intraperitoneal cisplatin and doxorubicin in patients with recurrent ovarian cancer and peritoneal carcinomatosis. Gynecol Oncol 150(1): 23-30, 2018.

36 Giger-Pabst U, Solass W, Buerkle B, Reymond MA and Tempfer CB: Low-dose pressurized intraperitoneal aerosol chemotherapy (PIPAC) as an alternative therapy for ovarian cancer in an octogenarian patient. Anticancer Res 35(4): 2309-2314, 2015.

Received October 25, 2018

Revised November 10, 2018

Accepted November 13, 2018 